\title{
Research Paper: Pilot Design of Ergonomic Bench for the Elderly With Anthropometric Approach
}

\author{
Afsaneh Eyvazi ${ }^{1}$, Hamidreza Mokhtarinia $^{1^{*}}$ \\ 1. Department of Ergonomics, University of Social Welfare and Rehabilitation Sciences, Tehran, Iran.
}

Citation Eyvazi A, Mokhtarinia H. Pilot Design of Ergonomic Bench for the Elderly With Anthropometric Approach. Physical Treatments. 2017; 7(3):123-132. http://dx.doi.org/10.32598/ptj.7.3.123

: http://dx.doi.org/10.32598/ptj.7.3.123

Funding: See Page 130

(c) Copyright: The Author(s)

\section{Article info:}

Received: 20 Jan 2017

Accepted: 20 May 2017

Available Online: 01 Oct 2017

Keywords:

Elderly, Ergonomics, Anthropometry, Aged

\begin{abstract}
A B S T R A C T
Purpose: With the global growth of elderly population, their increasing need to public and recreational spaces has become a novel challenge. Such spaces should be designed based on ergonomic principles in order to decrease their risk of injury. This research aimed to design an ergonomic bench for the elderly people with respect to their anthropometric dimensions.
\end{abstract}

Methods: In this descriptive study, 90 older participants, 24 females and 66 males, aged over 60 years, were recruited by cluster sampling method. A trained ergonomists measured their 13 anthropometric dimensions based on ISO (7250-1:2008). The dimensions of the available benches in the parks were also measured. Then, the fitness of elderly's anthropometric parameters were compared with the dimensions of the benches $(\mathrm{N}=100)$ in the parks. We also explored the problems and difficulties of the using benches by "future workshop technique". A total of 40 elder subjects were participated in the workshop (recruited by convenience sampling method). They were asked about their problems in using the benches. Their comments and suggestion were sorted and prioritized. Then, using CATIA software and considering the proposed solutions, a pilot ergonomic bench was designed in accordance with the elder anthropometric dimensions. The descriptive and inferential analyses were done by SPSS V. 16.

Results: Descriptive results of the anthropometrics dimensions of the older people including Mean, Standard Deviation (SD) as well as percentiles, frequency, cumulative frequency, percentage, Mean and SD for the dimensions of the benches were provided. The study results show a significant difference between the bench seating depth and elderly's buttock-popliteal length, also between bench seating width and elderly's buttock width, and finally between bench backrest height and elderly's shoulder height. There was no significant difference between bench seating height of concrete benches and popliteal height dimension, as well as between elbow rest height of iron benches and arm support height.

Conclusion: The elderly take undesirable postures during sitting on incompatible furniture (knee bending, trunk flexion, twisting, etc.).These unnatural postures impose physical strain on them. It is recommended that an anthropometric database of older adults be prepared so that new adjustable furniture can be designed based on these data.

\footnotetext{
* Corresponding Author:

Hamidreza Mokhtarinia, $P h D$

Address: Department of Ergonomics, University of Social Welfare and Rehabilitation Sciences, Tehran, Iran.

Phone: +98 (912) 2495248

E-mail: hrmokhtarinia@yahoo.com
} 


\section{Introduction}

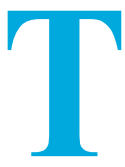

he changes in the population pyramid and increase in older people have created a special time period in the world current situation and especially Iran. The statistics also confirm that the proportion of elderly people has risen worldwide over the past decades. Increased average life expectancy of human beings due to fast advancement in medicine and technology along with declining birth rates in advanced countries are the reasons for this change in the elderly population [1-3].

Because of their age and reduced work activities, the elderly are a social group that mainly use urban spaces for voluntary and social activities [4]. Although most elderly people have a healthy and active life, aging is usually accompanied by decreased functional capacity and possibility of more disability due to accidents and illnesses. Therefore, development of systems and therapeutic interventions, which can provide a healthy and independent life for the elderly, are one of the main today's challenges. This challenge is especially on the shoulder of human resource engineers, because the main focus of this field is to design suitable systems for user groups.

Human resource engineering (ergonomics) is a science based on human abilities, limitations, and other design specifications. Matching the interaction between equipment and individual needs can minimize functional limitations and may even affect the process of disability. Thus, ergonomists should change the design of work places and products or seriously create new designs by considering the elderly [5]. To achieve these goals, ergonomists use different tools and techniques and anthropometry is one of the oldest one [6]. Anthropometry is a branch of science which deals with measurements of dimensions, weight, and ratios of the human body in order to reach comfortability, suitability, and usability [7].

Some studies have shown that the elderly frequently use the equipment not proportionate with their anthropometric status, because designs of urban spaces furniture, for instance, is based on decisions not corresponding with the elderly' needs. Public seats and benches available in the city are inappropriate and very inconsistent to the elderly's physical, mental, and psychological needs. As a result, the elderly are at risk of negative effects of the bad and inappropriate design of the furniture due to their long time sitting on them. Appropriate sitting and standing are the most important factors in the prevention of skeletal disorders. Improper sitting posture is one of the most significant factors which may increase the risk of developing skeletal disorders [8]. Furthermore, with the aging process, the elderly use the least power in their muscles and movement of joints, so musculoskeletal disorders in the elderly could be prevented by helping them to have a good posture. As mentioned before, the elderly usually stay in the sitting position for a long time every day; static and long time sitting in a forward curved position often imposes severe pressure on the muscles and ligaments, particularly on spine disks [9].

Regarding the time spent in urban spaces and especially in sitting conditions by older people, suitability of seats and benches to meet their needs is essential. In light of these facts and the elderly's obvious need to use public spaces, adaptation of these spaces to their sensory and physical needs will help their relaxation. Consequently, it seems necessary to have an urban furniture design consistent with aging conditions, considering the principles of ergonomics, and user suggestions. The purpose of this study was to design and develop a comprehensive usercentered product with a number of features which will make it suitable for the elderly and satisfy their needs. Therefore, in this study we tried to design a product (city bench) for the elderly by using ergonomic methods and taking advantage of older people opinions.

\section{Materials and Methods}

This was a descriptive survey study conducted in 2016. Our study participants were the elderly people over 60 years of age living in Tehran City, Iran. Sampling was carried out in two stages. In the first stage, which was related to the measurement of anthropometric dimensions, subjects aged over 60 years were selected using cluster sampling method from different nursing homes of Tehran. The total number of participants was 90 (24 women and $66 \mathrm{men}$ ) in this stage. In the second stage (future workshop technique), the participants were the elderly who came to the parks and used existing benches. They were selected using available sampling method. The number of participants at this stage was 40 .

The measuring instrument included a scale, tape meter, calipers and adjustable seats. CATIA software was used in the design section. SPSS V. 16 and the ICC test were used in checking the repeatability, accuracy of the ergonomist's measurements, and anthropometric data percentiles. Future workshop data were also evaluated descriptively.

To check the compatibility of existing bench dimensions with elderly's anthropometric dimensions, at first the available benches and anthropometric dimensions 
of the participants were measured. Then the technique of the future workshop was implemented. Next, CATIA software designed the ergonomic bench using the obtained data of these stages.

To obtain the specifications of the benches used by the elderly, the relevant data were supposed to be collected from the manufacturer of these benches and reviewing their standards. Phone calls and personal visits of some of these companies to obtain the dimensions of benches and attempts to find a standard for the elderly bench failed. Therefore, the benches in the parks of the north, south, west and east of Tehran were observed and their specifications measured and recorded. Then, a trained ergonomist (familiar with the measurement methods) measured the anthropometric dimensions of the elderly. But before the main measurement, in order to verify the reliability and measurement accuracy, ten anthropometric dimensions of 20 individuals were measured and then the repeatability was investigated through the Intra-class Correlation Coefficient (ICC).

The measurements were performed at two different time points and the $\mathrm{ICC}_{(2.1)}$ model was used for calculation. Then, the study measurements were carried out on the main samples. Only people entered the study who had normal physical health, without any apparent physical deformation. Those who could not stand for a long time during the measurement were excluded from the study. To measure physical dimensions, the qualified people entered a separate room, and their consent regarding the study was obtained by observing the relevant codes of ethics. Objectives and study procedure were explained for the subjects. Duration of measurement for each person was about 15 minutes and they were allowed to rest between measurements, if needed. All participants dressed in casual clothes and did not wear shoes.

In order to encourage participation of individuals in designing the ergonomic bench, 40 elderly in two groups of 20 were used in the section of future workshop technique. These people were different from those individuals whose anthropometric dimensions were measured. Sampling at this stage was carried out by available sampling method and continued until data saturation and the lack of access to new information. The future workshop technique can be used as a tool in ergonomic projects and other issues related to work and life environments, such as to create a new perspective, make the necessary changes, identifying and finding acceptable and feasible solutions to fix problems and improving conditions. This technique was implemented in the following 5 phases:

\section{Preparation phase}

Encouraging people to participate and taking advantage of their ideas to solve problems.

\section{Experimental phase}

Collecting important issues and problems related to the target issue and prioritize them with scoring (The scoring method is such that all people are equally awarded seven votes and they can divide their votes among the three first reasons from their point of view. This is done in such a way that two of the most important causes, which their elimination would impact the most on promoting the ergonomic bench level, each would gain 3 points and the third reason 1 point).

\section{Fantasy phase}

Collecting solutions to address the causes and problems mentioned in the previous phase, regardless of restrictions which may exist in everyday life.

\section{Strategy phase}

Choosing the best solutions to solve the problems encountered in the experimental phase, taking into account the existing restrictions.

\section{Follow-up phase}

Implementing suggested solutions and strict monitoring of its implementation [10].

\section{Results}

Tables 1 and 2 show the results of measuring the dimensions of the existing benches. In this part, 20 different bench types were measured which were divided into three general categories of wooden, iron and concrete benches and some of their parameters are presented in Tables 1 and 2 .

Table 3 presents the results of descriptive statistics regarding measurement of the anthropometric dimensions of elderly women and men. The participants in this study stage mentioned the most important problems of using the benches in the city. The problems are presented in three general categories: seating area, aesthetic, and support problems. Among these problems, the following three reasons earned the highest scores: Inappropriate seating area slope: 43 points; Existing benches are not long enough to accommodate more people together: 33 points; Absence of lumbar pad in the backrest area: 27 points. 
Table 1. Frequency of benches based on material used

\begin{tabular}{cccc}
\hline Material & Frequency & Percentage & Cumulative Frequency Percentage \\
\hline Wooden & 7 & 35 & 35 \\
Iron & 9 & 45 & 80 \\
Concrete & 4 & 20 & 100 \\
\hline
\end{tabular}

PHYSICAL TREA $\ M E N T S$

At the end of the study, the proposed solutions to address the causes mentioned in the experimental phase were identified. Fourteen proposed solutions were presented to improve the ergonomic situation of benches used by the elderly, the most important of them were as follows: fitting the height of the benches, embedding holes in the seating area to drain the accumulated rain and snow in the winter, erecting suitable canopies for benches (with the possibility of opening and closing), applying appropriate lumbar pad on backrest, adding containers to put mobile tools (shopping bag, cane, cup and so on).

In another part of the study, appropriateness of anthropometric dimensions of the elderly with some bench dimensions including depth of seating, seat width, rack height, elbow support height, and the back-support height were examined. Given the variety of existing benches, to increase the accuracy of calculations and the obtained results, the benches were divided into wooden, iron and concrete ones. The matching of the desired dimensions in two groups of elderly men and women was compared. The obtained results are presented in Tables 4 and 5 .

Results of Table 4 show a difference between the $5^{\text {th }}$ percentile and the buttock-popliteal length in both groups of men and women as well as between the seating area height and the $5^{\text {th }}$ percentile of this dimension in the women's population in all three types of benches. The seat height in the elderly men was only proportion- ate with the average height of concrete benches. Because concrete benches constitute only $20 \%$ of the study benches, the matching of this dimension of the benches with the elderly body composition is low.

There was also a difference between the $95^{\text {th }}$ percentile of shoulder height of the elderly men and women with backrest height of all three types of benches. On the other hand, if we examine appropriateness of the recommended amount of $50 \mathrm{~cm}$ Pheasant with the backrest height of the benches, we find no appropriateness between the height of the backrest of the benches and the recommended Pheasant value.

In relation to the width of the seating area of the benches for more than 1 individual, the proposed values of Pheasant is $50 \mathrm{~cm}$ per person. The results of Table 5 show a difference between the average seat width of all three types of benches with the recommended value. Wooden transverse benches have a width more than that amount and iron and concrete benches have a lower width of seating capacity. Moreover, for having a proper position in sitting position, shorter elbow support is more suitable than the higher height. As recommended by the Pheasant [11], the height of the elbow support is generally considered to be 20 to $25 \mathrm{~cm}$ above the level of the seating area. In this study, concrete benches lacked elbow support, therefore, we only examined the proportion of this dimension with wooden and iron benches.

Table 2. Descriptive statistic parameters of available bench dimensions used by the elderly (dimensions in $\mathrm{cm}$ )

\begin{tabular}{|c|c|c|c|c|c|c|}
\hline \multicolumn{2}{|c|}{ Descriptive Statistics } & $\begin{array}{c}\text { Length of Seating } \\
\text { Area }\end{array}$ & $\begin{array}{c}\text { Depth of Seating } \\
\text { Area }\end{array}$ & $\begin{array}{c}\text { Height of Seating } \\
\text { Area }\end{array}$ & $\begin{array}{l}\text { Height of Total } \\
\text { Backrest Support }\end{array}$ & $\begin{array}{l}\text { Height of Elbow } \\
\text { Support }\end{array}$ \\
\hline \multirow{3}{*}{ Mean } & Wooden bench & 165 & 39.1 & 41.5 & 39.2 & 23 \\
\hline & Iron bench & 147.6 & 38.8 & 42 & 46.3 & 19.4 \\
\hline & Concrete bench & 135 & 40 & 40.2 & 41.3 & - \\
\hline \multirow{3}{*}{ SD } & Wooden bench & 15.3 & 7.6 & 2.2 & 5 & 1.4 \\
\hline & Iron bench & 14.6 & 3.1 & 3.3 & 3.7 & 3.6 \\
\hline & Concrete bench & 38.2 & 11.2 & 3.2 & 5.7 & - \\
\hline
\end{tabular}


Table 3. Descriptive statistics and percentiles of gender-specific anthropometric dimensions of the elderly

\begin{tabular}{|c|c|c|c|c|c|c|}
\hline Dimensions & & Mean & SD & $5^{\text {th }}$ Percentile & 50 $0^{\text {th }}$ Percentile & 95 ${ }^{\text {th }}$ Percentile \\
\hline & Women & 62.2 & 7.44 & 49 & 60 & 76.3 \\
\hline \multicolumn{7}{|l|}{ Weight } \\
\hline & Men & 71.2 & 11.12 & 52.4 & 70 & 89.6 \\
\hline & Women & 154.2 & 6.47 & 143 & 154 & 165.7 \\
\hline \multicolumn{7}{|l|}{ Height } \\
\hline & Men & 165.6 & 6.97 & 153 & 165 & 176.7 \\
\hline & Women & 81.5 & 5.8 & 68.5 & 81.5 & 89.3 \\
\hline \multicolumn{7}{|l|}{ Sitting height } \\
\hline & Men & 87.6 & 4.2 & 80.6 & 88.6 & 94.1 \\
\hline & Women & 55.3 & 3.4 & 43.8 & 55.5 & 61 \\
\hline \multicolumn{7}{|l|}{ Sitting shoulder height } \\
\hline & Men & 59.8 & 2.6 & 53.7 & 60 & 63.7 \\
\hline & Women & 34 & 2.3 & 29.2 & 34.1 & 37 \\
\hline \multicolumn{7}{|l|}{ Sitting shoulder-elbow length } \\
\hline & Men & 36.5 & 1.8 & 32.1 & 37 & 39 \\
\hline & Women & 21.2 & 2.8 & 13.5 & 22.5 & 24 \\
\hline \multicolumn{7}{|l|}{ Sitting elbow support height } \\
\hline & Men & 23.1 & 1.9 & 19.3 & 23 & 25.8 \\
\hline & Women & 50.6 & 1.9 & 46.8 & 50.8 & 54 \\
\hline \multicolumn{7}{|l|}{ Sitting knee height } \\
\hline & Men & 54.2 & 2.5 & 50 & 54.3 & 58 \\
\hline & Women & 40.6 & 2.3 & 37.6 & 40.2 & 45.1 \\
\hline \multicolumn{7}{|l|}{ Sitting popliteal height } \\
\hline & Men & 43.4 & 2.5 & 40.2 & 43 & 48.1 \\
\hline & Women & 52.9 & 2.7 & 48.6 & 52.4 & 56.8 \\
\hline \multicolumn{7}{|l|}{ Knee-seating area length, sitting } \\
\hline & Men & 56.3 & 2.9 & 50.8 & 56.7 & 61.2 \\
\hline & Women & 43.5 & 3.3 & 38 & 43.6 & 48 \\
\hline \multicolumn{7}{|l|}{ Buttock-Popliteal length } \\
\hline & Men & 46.3 & 2.6 & 41.6 & 46.5 & 50.3 \\
\hline & Women & 35.7 & 2.5 & 31.4 & 35.5 & 40.5 \\
\hline \multicolumn{7}{|l|}{ Width of seating area, sitting } \\
\hline & Men & 34.7 & 2.7 & 31 & 34.4 & 39.8 \\
\hline & Women & 38.4 & 1.2 & 43.3 & 38.9 & 41.8 \\
\hline \multicolumn{7}{|l|}{ Width of shoulder } \\
\hline & Men & 42 & 2.5 & 38.1 & 41.8 & 46.2 \\
\hline & Women & 45.4 & 3.3 & 41.3 & 44.3 & 53.8 \\
\hline \multicolumn{7}{|l|}{ Elbow wide width } \\
\hline & Men & 47.9 & 4.5 & 40.3 & 48 & 55.9 \\
\hline
\end{tabular}


Table 4. Studying the appropriateness of anthropometric measurements of the elderly people with the dimensions of the existing benches

\begin{tabular}{|c|c|c|c|c|}
\hline & Dimensions & & Target Percentile & Mean of Target Dimension \\
\hline \multirow{8}{*}{$\begin{array}{l}\text { Comparing mean scores of depths } \\
\text { of seating area of the bench with } \\
5^{\text {th }} \text { percentile of buttock-popliteal } \\
\text { length of the elderly }\end{array}$} & \multirow{3}{*}{ Wooden bench } & Women & 38 & 39.1 \\
\hline & & & & \\
\hline & & Men & 41.6 & 39.1 \\
\hline & \multirow{2}{*}{ Iron bench } & Women & 38 & 38.8 \\
\hline & & Men & 41.6 & 3.8 \\
\hline & \multirow{3}{*}{ Concrete bench } & Women & 38 & 40 \\
\hline & & & & \\
\hline & & Men & 41.6 & 40 \\
\hline \multirow{8}{*}{$\begin{array}{l}\text { Comparing mean scores of seating } \\
\text { area height of the bench with } 5^{\text {th }} \\
\text { percentile of popliteal height of } \\
\text { the elderly }\end{array}$} & \multirow{3}{*}{ Wooden bench } & Women & 37.6 & 41.5 \\
\hline & & & & \\
\hline & & Men & 40.2 & 41.5 \\
\hline & \multirow{2}{*}{ Iron bench } & Women & 37.6 & 42 \\
\hline & & Men & 40.2 & 42 \\
\hline & \multirow{3}{*}{ Concrete bench } & Women & 37.6 & 40.2 \\
\hline & & & & \\
\hline & & Men & 40.2 & 40.2 \\
\hline \multirow{8}{*}{$\begin{array}{c}\text { Comparing mean scores of backrest } \\
\text { support of the bench with } 95^{\text {th }} \\
\text { percentile of shoulder length of } \\
\text { the elderly }\end{array}$} & \multirow{3}{*}{ Wooden bench } & Women & 61 & 39.2 \\
\hline & & & & \\
\hline & & Men & 63.7 & 39.2 \\
\hline & \multirow{2}{*}{ Iron bench } & Women & 61 & 46.3 \\
\hline & & Men & 63.7 & 46.3 \\
\hline & \multirow{3}{*}{ Concrete bench } & Women & 61 & 41.3 \\
\hline & & & & \\
\hline & & Men & 63.7 & 41.3 \\
\hline
\end{tabular}

The results of Table 5 show that average elbow support on wooden bench matches with the recommended value for this dimension. But it should be noted that among 7 wooden benches measured in this study, only 2 benches had elbow support which accounts for $28 \%$ of all benches. This reflects that the fitness of this dimension of benches with the elderly's dimensions is poor.

The review of the above results shows that in most cases there is a difference between the anthropometric

Table 5. Studying appropriateness of anthropometric dimensions of the elderly with the existing bench dimensions

\begin{tabular}{llcr}
\hline \multicolumn{2}{c}{ Dimensions } & Recommended Value & Mean Score of the Target Dimension \\
\hline $\begin{array}{c}\text { Comparing mean score of seating } \\
\begin{array}{c}\text { area width of the bench with seating } \\
\text { area width of the elderly }\end{array}\end{array}$ & Iron bench & 151.9 & 165 \\
$\begin{array}{c}\text { Comparing mean score of elbow } \\
\text { support height of the bench with } \\
\text { forearm height of the elderly }\end{array}$ & Wooden bench & 151.9 & 135 \\
\hline
\end{tabular}




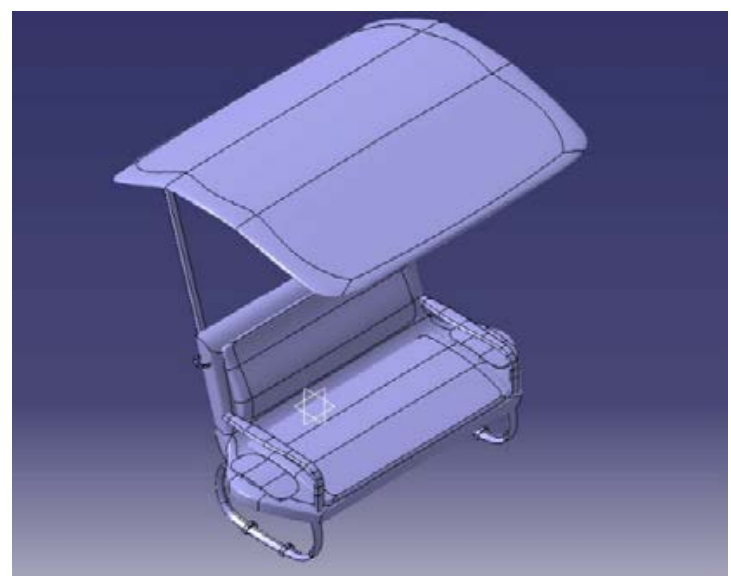

PHYSICAL TREA TMENTS

Figure 1. The image obtained using CATIA software from front view

dimensions of the benches measured and the recommended dimensions, which reflects the poor matching of benches in the city with anthropometric dimensions of the elderly. Therefore, once again, the necessity of designing an ergonomic bench for the elderly becomes obvious. Eventually, using the results of measuring the anthropometric dimensions of the elderly and the future workshop technique, CATIA carried out the designing process in a conceptual design environment. Pictures of the designed bench are displayed in Figures 1, 2, and 3.

\section{Discussion}

Every human experience sitting several times a day, especially older people who do sitting for longer duration because of their physical conditions and lives, so effects of long time sitting with multiple skeletal and muscular problems also appear in them. Therefore, designing furniture based on anthropometric data is one of the requirements for this group of society. The current study is the first study in our country which examined and determined the physical dimensions of the elderly using the anthropometric approach.

The main purpose of this study was to provide the required anthropometric dimensions to design work and life equipment for the elderly in Iran. In this study, the physical dimensions of 90 elderly people in Tehran were measured by referring to nursing home care centers. Then, using the future workshop technique, the older study participants identified some of the problems in using benches and offered some solutions including matching the height of the bench seat. For this purpose, $5^{\text {th }}$ percentile of women's popliteal height was considered as the height of the benches. Also, a porous sponge layer was installed over the seating area, preventing the

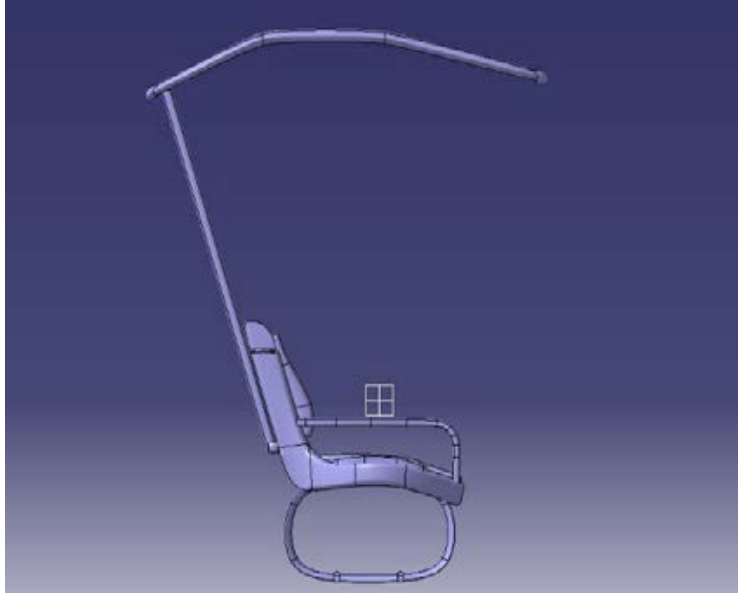

PHYSICAL TREA $\$ MENTS

Figure 2. The image obtained using CATIA from the side view accumulation of rain and snow water while adding the softness to the seating surface.

In the backrest support also, a layer of the same material was used which worked as a lumbar pad on the back. According to the recommendations of the participants, a part was also added to hold the portable tools and the walking stick. Moreover, to prevent direct sunlight exposure in summer and snow and rain in winter, a canopy with opening and closing capability was installed. This bench has been designed for two people, while changing its longitudinal dimension allows designing and building the bench for more people. Also, in order to determine the proportion of dimensions of the existing bench with the anthropometric dimensions of the elderly, we measured the dimensions of the existing benches. Eventually by taking into account the above-mentioned issues, an ergonomic bench for the elderly was designed.

However, comparing anthropometric dimensions of Iranian elderly with the elderly of other countries is difficult due to some reasons such as sample size, specific

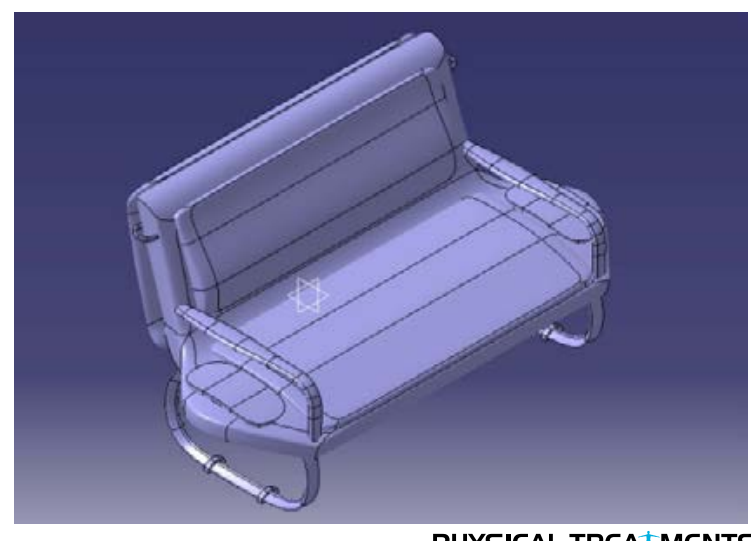

PHYSICAL TREA MENTS

Figure 3. The obtained image without canopy using the CATIA 
conditions of measurement, ethnic composition, obsolete data, health status of participants, etc. In spite of that, comparison of some physical dimensions of Iranian men with older men of other countries such as Australia [2] and Malaysia [8] shows that the width of the buttock, which is a necessary factor in the design of the width of the bench seat, as well as shoulder width used in the back of the bench, is larger in elderly Iranians. Sitting position height and the elderly popliteal height of older Iranian are also greater than those in older Australians. In the meantime, only height of Australian male subjects is slightly higher than that of Iranian subjects.

On the other hand, height of Iranian male subjects is greater than that of Malaysian subjects. But the Malaysian elderly were larger in other dimensions; sitting height, popliteal height, the width of the sitting area and shoulder. Comparison of anthropometric dimensions of Iranian elderly women with Polish [1] and Australian [2] elderly women showed that height, height of sitting, and popliteal height of elderly Iranian woman is greater than those of the Polish elderly woman, while the width of seating area and shoulder of the Polish elderly were larger than those in Iranian subjects. Physical dimensions of Iranian elderly women including height, height of sitting, popliteal height, width of seating area, shoulder width, knee height, knee-seat length, are larger than those of Australian elderly woman.

This difference in anthropometric measurements can be attributed to differences in ethnicity, race, diet, and socioeconomic factors. Since racial characteristics are important and influential factors in product design, work space, dress, tools and furnishings design, measuring body dimensions in different races is very important to determine these specifications [12]. Therefore, designing based on anthropometric data is one of the requirements for the elderly community.

Of the limitations of this study was absence of healthy elderly and their participation in the measurement of dimensions. Another limitation was lacking a specific standard for the dimensions of the benches used in urban spaces.

\section{Ethical Considerations}

\section{Compliance with ethical guidelines}

All ethical principles were considered in this article. The participants were informed about the purpose of the research and its implementation stages; They were also assured about the confidentiality of their information; Moreover, they were allowed to leave the study whenever they wish, and if desired, the results of the research would be available to them.

\section{Funding}

This research was extracted from the MSc. thesis of the first author, in the Department of Ergonomics, University of Social Welfare and Rehabilitation Sciences.

\section{Conflict of interest}

The authors declared no conflict of interest.

\section{Acknowledgements}

The authors hereby express their sincere gratitude to officials and professors of the Hamadan University of Medical Sciences, and nurses and managers of the retirement home who helped us in this study. Also we thank to Welfare Organization of Tehran Province, directors and nurses of the retirement home and the elders who participated in the project.

\section{References}

[1] Jarosz E. Anthropometry of elderly women in Poland: Dimensions for design. International Journal of Industrial Ergonomics. 2000; 25(2):203-13. [DOI:10.1016/S01698141(99)00011-6]

[2] Kothiyal K, Tettey S. Anthropometry for design for the elderly. International Journal of Occupational Safety and Ergonomics. 2001; 7(1):15-34. [DOI:10.1080/10803548.2001 .11076474] [PMID]

[3] Wu HC, Chiu MC, Hou CH. Nail clipper ergonomic evaluation and redesign for the elderly. International Journal of Industrial Ergonomics. 2015; 45:64-70. [DOI:10.1016/j.ergon.2014.12.002]

[4] Marcus CC, Francis C. People places: Design guidlines for urban open space. Hoboken, N. J.: John Wiley \& Sons; 1997.

[5] Rice VJ. Ergonomics in health care and rehabilitation. Portsmouth, New Hampshire: Heinemann Publishing; 1998.

[6] Mokdad M, Al-Ansari M. Anthropometrics for the design of Bahraini school furniture. International Journal of Industrial Ergonomics. 2009; 39(5):728-35. [DOI:10.1016/j. ergon.2009.02.006

[7] Hanson L, Sperling L, Gard G, Ipsen S, Vergara CO. Swedish anthropometrics for product and workplace design. Applied Ergonomics. 2009; 40(4):797-806. [DOI:10.1016/j. apergo.2008.08.007] [PMID]

[8] Dawal SZ, Ismail Z, Yusuf K, Abdul-Rashid Sh, Shalahim NS, Abdullah NS, et al. Determination of the significant anthropometry dimensions for user-friendly de- 
signs of domestic furniture and appliances: Experience from a study in Malaysia. Measurement. 2015; 59:205-15. [DOI:10.1016/j.measurement.2014.09.030]

[9] Vink P. Comfort and design: Principles and good practice. Boca Raton, Florida: CRC Press; 2004. [DOI:10.1201/9781420038132]

[10] Helali F, Lönnroth EC, Shahnavaz H. Participatory ergonomics intervention in an industrially developing country: A case study. International Journal of Occupational Safety and Ergonomics. 2008; 14(2):159-76. [DOI:10.1080/1 0803548.2008.11076760] [PMID]

[11] Pheasant S, Haslegrave CM. Bodyspace: Anthropometry, ergonomics and the design of work. Boca Raton, Florida: CRC Press; 2016. [DOI:10.1201/b21331] [PMCID]

[12] Lin YC, Wang MJ, Wang EM. The comparisons of anthropometric characteristics among four peoples in East Asia. Applied Ergonomics. 2004; 35(2):173-8. [DOI:10.1016/j. apergo.2004.01.004] [PMID] 
